Kemp Sharon (Orcid ID: 0000-0002-0489-4350)

Coles-Black Jasamine (Orcid ID: 0000-0002-8358-3779)

Mukherjee Payal (Orcid ID: 0000-0003-1095-1566)

17

Ethical and regulatory considerations for surgeons as consumers and creators of 3D printed devices

TITLE PAGE

\title{
ETHICAL AND REGULATORY CONSIDERATIONS FOR SURGEONS AS CONSUMERS AND CREATORS OF 3D-PRINTED MEDICAL DEVICES
}

\author{
S Kemp MBBS PhD; ; $^{*}$ J Coles-Black MBBS; bc M J Walker PhD; ${ }^{\text {def }}$ Gordon Wallace FRACI \\ DSc; ${ }^{f}$ Jason Chuen FRACS MPH; ${ }^{\text {bc }}$ P Mukherjee, FRACS MS ${ }^{\text {ag }}$
}

anstitute of Academic Surgery, Royal Prince Alfred Hospital, Sydney, NSW, Australia.

b3d Medical Printing Laboratory, Austin Health, Heidelberg, VIC, Australia.

${ }^{\mathrm{c}}$ The University of Melbourne, Parkville, VIC, Australia.

${ }^{\mathrm{d}}$ Department of Religion and Philosophy, Hong Kong Baptist University, Kowloon, HK

eDepartment of Philosophy, Monash University, Melbourne, Australia.

${ }_{\mathrm{f}}^{\mathrm{f}}$ ARC Centre of Excellence for Electromaterials Science, Intelligent Polymer Research Institute, University of Wollongong, Wollongong, Australia.

gUniversity of Sydney, Sydney, NSW, Australia.

This is the author manuscript accepted for publication and has undergone full peer review but has not been through the copyediting, typesetting, pagination and proofreading process, which may lead to differences between this version and the Version of Record. Please cite this article as doi: $10.1111 /$ ans.15871

This article is protected by copyright. All rights reserved. 
* Corresponding author: Dr Sharon Kemp, Institute of Academic Surgery, Royal Prince Alfred Hospital, Sydney, NSW, Australia. Tel: +61 404699244 Email address: drsharonkemp@gmail.com.

Word count: 3984 (including table and references)

Key words: 3D printing; additive manufacturing; ethical considerations; surgery. 


\section{MAIN TEXT}

\section{Introduction to 3DP in surgery}

Surgeons strive to deliver state-of-the-art care whilst ensuring sustainability and equitable access. We have a natural desire to seek out and utilise new techniques, with every operation as unique as the patients we treat. Customisation of care sits in everyday decision making as surgeons navigate deviating from "standard” treatment vs exposing patients to additional or unknown risks in order to achieve the best patient outcomes. Since its inception in the 1980s,[1] three-dimensional printing (3DP) has progressively transformed the field of surgery with its rapid adoption explained in its ability to satisfy these core surgical values. 3DP not only supports the ability to customise solutions to patients, but other values such as collaboration in multidisciplinary teams, push creativity in delivering problem-based solutions, and dramatically opens the ability for cost reduction.

Applications of 3DP in surgery include patient-specific 3DP designs for implants and prostheses,[2] surgical instruments and guides,[3] models for surgical planning,[4] training,[5] patient education,[6] and even preparation of dose-specific medications.[7] 3DP PSIs and preoperative planning tools have been reported to improve surgical outcomes,[8] as well as cost and waste reductions. However, rapid adoption has outpaced regulation. New regulation now calls into question the definition of medical devices, manufacturer and supplier and presents ethical concerns regarding ownership of human 3D data, risk and liability of the medical practitioner and hospital, sustainability of research and data collection upon which policy 
reform can be based. This discussion paper highlights such ethical concerns for the surgeon as both a consumer and creator of a new generation of medical devices.

\section{Adoption of 3DP technology in surgery}

Adoption of technology in surgery has been studied through numerous perspectives such as ethical translation (IDEAL guidelines), technology and market-based translation (Gartner's hype phase of technology) as well as personality-based translation (adoption curve).[9, 10] In addition, ease of use, impact on patient outcome, industry strategy and government policy also play a role. However, at a practical level, adoption of medical devices is significantly impacted by reimbursement. In Australia, reimbursement is heavily influenced by regulation which in turn is influenced by safety and efficacy data of respective medical devices. However, when a technology can have the power to dramatically reduce cost, such as 3DP, adoption may outpace regulation, thus opening the pathway for evaluation-based implementation as opposed to regulation-based implementation.

Research and data driven implementation, i.e. evaluation-based implementation, can drive down costs of attaining safety and efficacy data if surgical academics are invited to be part of the solution, not just consumers of the technology. Particularly, with 3DP, this may be a more sustainable model which leads to increased adoption and faster implementation with increased visibility and data exchange between researchers, hospitals, government and regulatory bodies. In contrast, regulation-based implementation of medical devices in Australia is slow 
and expensive and cannot keep pace with the rate of innovation of 3D printing, and as a consequence will increase the cost of the very technology whose significant appeal is cost reduction, thus reducing the adoption of the technology.

Low-risk applications such as patient-specific 3D anatomical models for use in self-education or preoperative planning may hold immense benefit to surgeons while having little implication on patient safety. But with high-risk applications such as 3DP PSIs, governance and regulatory mechanisms are unable to keep pace with innovation, and adoption raises significant ethical concerns for the community as a whole. In Australia, this has been particularly challenging for the TGA (Therapeutic Goods Administration),[11] which is responsible for regulation and safety of medicines and medical devices, especially in the absence of mandatory prospective monitoring of long-term risks.

The challenges demonstrated by 3DP in surgery encompass a wider systemic concern: are current regulatory frameworks reasonably able to cope with the rapid changes in health care technology? While our regulatory frameworks struggle to adapt to the rapid changes in technology evolution, it is vital that academic surgeons and their research teams, as both creators and consumers of this technology, take a leadership role in health advocacy, evaluation, ethical transition and long-term monitoring of these applications. While both evaluation-based implementation and regulation-based implementation are important, the current status quo is the latter. To achieve sustainable and equitable future health care, the challenges of 3DP force us to re-evaluate if evaluation-based implementation can be incorporated earlier in our translational pathways, in partnership with regulatory bodies. Industry, academics, regulators, 
funders and clinicians can and should do better to be collectively engaged with evaluation and reform of the current translational pathways of health technology.

\section{Evidence of safety and efficacy}

It is difficult for policy makers to prospectively plan reimbursement strategies without evidence of benefit, further limiting scale and adoption of technologies. However, it is difficult for academics to improve data collection, if overregulation impacts on costs of not only current research but also further reduces funding for prospective registries and databases for health economic assessment.

Currently, there is a paucity of clinical trials data, particularly given that PSIs are produced and used once only, such that standard experimental trial designs are impractical. Literature on the clinical efficacy and effectiveness of 3DP in surgery is growing, however the majority of studies are for anatomical models and guides for surgery,[12] given the lower risk to patient safety. Diment et al. reported claims of decreased operation times and increased surgical accuracy, mostly in the fields of Maxillofacial and Oral surgery,[13] which supports the results of older reviews,[8, 14] however given insufficient studies against controls with 3DP PSI, orthotics and prostheses, efficacy was not evaluated.[13] A large proportion of the literature consists of case series, poor-quality cohort studies, or single-site underpowered randomised clinical trials, which report either only qualitative results or positive outcomes which are clinically insignificant. 
Witowski et al. recently reviewed worldwide 3DP clinical trials (92 trials, 6252 patients) and demonstrated a surge in the quantity of trials being registered in recent years, again, primarily in fields of Orthopaedics, Maxillofacial Surgery and Dentistry.[15] However, similar to Diment et al., no statistical or pooled analyses could be performed given the diverse applications and disciplines using 3DP.[15] Encouragingly, however, the authors report 60 registered trials in the use of surgical templates, orthoses and 3DP PSI, to be completed by 2020. Subsequent meta-analysis of future clinical trials, and regularly updated systematic reviews, are necessary in order to give statistical power to the overall effectiveness, cost and impact on clinical outcomes. With increasing global utilisation of 3DP, collaboration is key to address this weakness. In addition, academics and administrators should share data and collaborate to establish hospital-based prospective registries as utilisation increases in the public and the private sectors.

\section{The impact of regulations on 3DP medical devices}

It is highly likely that point-of-care 3DP personalised devices, including complex and higher risk medical devices, will become routine. Regulations on the use of 3DP technology will play an important role in successful clinical implementation by protecting patients and setting quality standards for manufacture, and mandate long-term data of device safety by requiring device registration. To date, the lack of clear regulatory guidelines for personalised 3DP 
devices places frontline surgeons in challenging ethical decision-making roles as they balance not withholding innovative solutions for patients who otherwise face significant quality of life impairments, yet having insufficient long-term data to adequately attain informed consent. However, due to the diverse nature of applications for 3DP, regulation which is appropriate and necessary for high-risk applications may be inappropriate and restrict innovation for lowrisk applications such as orthotics and 3DP anatomical models.

Increasing regulation causes costs that can inadvertently reduce access, and some of the proposed new categorisations appear to reflect an overly strict assessment of risk such that even low risk devices, such as 3DP prostheses, will be highly regulated.[11] In addition, lack of clarity surrounding regulatory requirements may further hamper use and innovation. For example, if a surgeon wanted to practice a new procedure or one that hasn't been performed for a while, he or she may practice on cadaveric human tissue. This is not regulated by the TGA and its use requires compliance with the Anatomy Act. However, if a surgeon were to practice the same procedure using a 3DP patient-specific model which is lower in cost and anatomically more accurate, the surgeon would be using a medical device subject to regulation. If the same model was printed in-house, the surgeon would then be classed a manufacturer. If the surgeon made numerous copies of the model without any intention of using the procedure on the individual patient, but to teach trainees the principles of the same procedure, it would be exempt from regulation. 
To add further ethical complexity to the surgeon's routine practice, the data source of these 3D models, Xray files are classed as medical devices, raising concerns surrounding the ownership of human data. Incentivising a corporate ownership model of human data, in this case a personalised medical device, creates a slippery slope if an individual's anatomy should be commercialised as a medical device. It also causes significant discomfort about misuse of this data, which will be addressed later.

Some low-risk applications such as orthotics and prosthetics are not strictly regulated if made using traditional manufacturing methods. However, if manufactured using 3DP, they will come under new regulation. Here is technology that has the capacity to reduce health care costs via a digital workflow to improve access to remote patients and improve scale. However, over-regulation will disincentivise 3DP and cause clinicians to retreat towards traditional manufacturing. Without scale and adoption, it will it be difficult to promote new industry and economic growth, a focus of many governments globally. In addition, reduced adoption will reduce support and funding for academics to develop prospective databases to conduct health technology assessments for government, hampering evidence-based decisions regarding reimbursements. In direct contrast to the direction the TGA has taken, the American Medical Association has approved reimbursement codes for patient-specific 3DP anatomical models and surgical guides from 2019.

Regulatory bodies need to give careful consideration to such costs to patients and the health care system. The current regulatory cycle is reactive and slow-moving. For instance, the 
exclusion for custom made devices was set twenty years ago and has not been revised since. The TGA needs to shift from a "set and forget" model to an iterative approach. In effect, the same strategies employed by innovators should be used by those seeking to regulate them.

A further issue affecting surgeon-researchers is the need for international harmonisation of regulation. Internationally most medical device regulations will be based on the standards from the International Standards Organisation (ISO-10993), the International Medical Device Regulators Forum and the World Health Organisation, who have also published a global regulatory framework.[16] The classification of risk for medical devices also varies between countries, with 3DP and regenerative devices generally classified as ‘custom devices’.[16] With international trials both in 3DP and bioprinting, how is it possible to ensure that experimental research overseas will be done with the same rigorous regulations as Australia? Even if the international regulatory bodies collaborate, different laws and different levels of governance in the various countries, may be barriers for clinicians to enrol in international trials. This will result in surgeon-researchers moving to countries that provide a more hospitable legal and regulatory environment. This will also have a direct economic impact on Australian medical innovation, with commercialisation moving overseas, given the cost of starting a new Australian company when competing with large overseas multinationals.

Implementation of 3DP technology in clinical practice

This article is protected by copyright. All rights reserved. 
For the successful translation of 3DP surgical innovations, it is imperative for the team to be placed at point-of-care. However, control and implementation must be divided by low-risk and high-risk applications. While it is important for industry to take responsibility for quality control, safety and efficacy data, monitoring registries of high-risk applications, their financial sustainability should not seek to replace surgeon-led 3DP research laboratories involved in low-risk research and innovation. Not all innovation is commercially sustainable but may improve patient outcomes. The proposed regulatory reforms threaten to sacrifice needs-based innovation by clinicians for the financial sustainability of high-risk PSI providers, especially in Australia, where scale and adoption is further challenged by its relatively small population. In addition, industry should seek to engage and incorporate academics in the long-term analysis of both low and high-risk applications, so efficacy data on 3DP innovations do not solely originate from industry. In return, industry gains by reducing costs, as some of the cost of governance of this research is shared by academics and hospitals.

With increasing complexity of regulation and governance, literacy and credentialing of users of 3DP surgical innovations is also an important ethical issue regardless of the level of risk. Where does the responsibility lie for the safe introduction, utilisation and regulation of 3DP medical devices? Medical practitioners ultimately bear the medicolegal risk of poor outcomes. Hospitals share the medicolegal risks by checking the qualifications of surgeons (credentialing) and authorising those surgeons to provide services (privileging),[17] but with complex dynamics of access to new technology, who is responsible for ensuring adequate training? In 2017, the Washington State Supreme Court (U.S.) issued a decision that device 
manufacturers are also liable for ensuring that their product is safely adopted in clinical practice,[18] based on the case of Taylor vs Intuitive (creator of da Vinci robot), whereby a patient had a very poor outcome from a surgeon’s first unsupervised robotic prostatectomy.[19] The surgeon was very experienced at open prostatectomy, however had only very brief hands on training by Intuitive (Intuitive Surgical Inc, California, U.S.A.) and two-supervised cases with an experienced surgeon. Initially, the court was in favour of Intuitive, claiming that the risks were explained to the surgeon, however the court overruled this given that Intuitive had a duty to warn the hospital, about the risks and complications, placing liability on the manufacturer.[18] This gives manufacturers financial incentive to collaborate with credentialing bodies for training of surgeons and implementing any new 3DP surgical technology, however this raises conflict of interest concerns.[18] To circumvent this a combined approach including training with ongoing proctoring from experienced surgeons, rigorous credentialing processes, as well as collaboration with industry, would be the most sensible approach for the safe and effective introduction of 3DP medical devices into clinical practice.[20, 21] Surgeons, even those using 3DP for education and training, areas exempt from regulation, should have training and credentialing to allow literacy of the ethical and regulatory issues which will change according to the intended application.

A further change of role relates to the blurring of research and clinical practice, an issue that often arises in relation to surgical innovation. It is crucial to ensure that academics using innovative technologies and hospitals facilitating 3DP research develop prospective registries with input from health economist to collect long term data. In addition to monitoring the 
safety and effectiveness of these new devices (and their antecedent workflows), and recording new applications and new technology convergences, registries should prospectively measure the inpatient and outpatient costs including QOL costs, so there can be evidence-based reimbursement available for 3DP solutions based on benefit to the community. However the prospective register must not obstruct access and innovation via high application costs or onerous documentation requirements and be able to accommodate cases which cannot be categorised or potential innovations. This will require careful management to ensure quality data collection can be achieved and ethical requirements met without making data collection overly burdensome and delay patient care. This data will further ensure equitable access to these innovations, ensuring its use is truly disruptive in not just being able to push the frontiers of surgical management, but also ensure that as many patients as possible benefit from it.

Intellectual property and ownership of patient data

Protection of rights and patenting of new 3DP technology and medical devices is understandably significant for surgeons, academics, hospitals, industry and government, given the increased availability, and decreasing costs, of 3D printers, as well as the potential for commercialisation, particularly given many of the initial 3DP patents have now expired. Areas of potential IP in 3DP technology include printers and their component parts, design of 3D objects in digital files, materials, printing methods, and 3DP medical devices themselves. Software programs used in 3DP, such as programs designed to predict implant dimensions 
based on CT, may be protected by copyright laws and marketed under a particular trademark, but are difficult to patent, disincentivising clinicians from creating new designs. In addition, the proposed regulatory changes seek to regulate the software used for medical 3DP, but not who is qualified to operate the software. This results in potentially dangerous discrepancies between how, for example, the margins of cancer on imaging are interpreted by an engineer in industry, compared to the point-of-care treating surgeon or radiologist.

Since the introduction of the low-cost 3D printers items can be produced through commercial services or at home by simply downloading a digital file of an object, making the owner of the printer the manufacturer.[22] This raises significant IP challenges since digital files can be easily copied and distributed much more easily than 3D objects. In combination with a 3D scanner, available on smart phones, it will be possible to scan any object that has patent, copyright or trademark protection, and print copies without approval. Thus, there needs to be processes to protect the interests of individual patients in relation to privacy, and individual innovators in relation to financial rewards.

Another key issue relates to that of ownership of patient data. In an era which has witnessed manipulation and abuse of personal data for instance on social medial platforms, it is important to clarify who ultimately is the owner of digital data or physical models of individuals’ body parts: patients, radiologists, smart phone application developers, databases or data banks data, device manufacturers, doctors or hospitals. Adding more ethical complexity, there is disparity in rules in ownership of tissue, which may be increasingly 
incorporated into 3DP devices with advances in bioprinting. Some institutions allow personal ownership, while others take ownership of the tissue. Will stem cell banks progress along the lines of obstetric services for sperm and egg preservation facilities or will they progress towards biobanks which may be owned by an institution that will deliver the bioprinted solution on demand as necessary? What would happen to excess stem cells, once the application has been completed?

While these technologies are rapidly evolving, there is no parallel evolution of laws of privacy developed to ensure that patient data is not exploited. Yet, there are already international biobanks in place. With the advent of smart phone applications to 3D scan body parts, it is possible that, in the future, people may not even be aware of the existence of customised medical devices from their own body parts existing. The risk of incentivising commercialisation of 3D human data, essentially identical duplicates of human body parts, is extremely concerning and regulatory bodies should reconsider that it's not the human model that should be classed as a medical device, but rather the manufacturing process that needs to be regulated including software and hardware.

\section{$\underline{\text { Conclusion }}$}

In the near future, it is possible that with the convergence of new technologies such as 3DP, AI and robotics, automation of design will reduce both time and cost to produce 3DP medical 
devices, allowing faster and more complex manufacturing. In order to navigate this rapid evolution of 3DP technology, we require regularly updated reviews of clinical trials, frequently changing regulatory requirements and government policies to meet technological advances, as well as industry support (Table 1). For this to be successful and society as a whole to benefit from innovation, a combined approach is imperative where surgeons engage in discussion and collaboration with academics, scientists, hospitals, laboratories, government and industry as well as developing a platform to discuss issues concerning their role as both consumers and creators of 3DP technology and medical devices. Finally, an innovative regulatory process is required to keep up with 3DP in surgery; one which is iterative like the new technologies it is seeking to regulate. 


\section{REFERENCES}

1. Hull, C.W., Patent 4575330: Apparatus for production of three-dimensional objects by stereolithography. 1986: U. S.

2. Jacobs, C.A. and A.Y. Lin, A New Classification of Three-Dimensional Printing Technologies: Systematic Review of Three-Dimensional Printing for Patient-Specific Craniomaxillofacial Surgery. Plast Reconstr Surg, 2017. 139(5): p. 1211-1220.

3. George, M., et al., 3D Printed Surgical Instruments: The Design and Fabrication Process. World J Surg, 2017. 41(1): p. 314-319.

4. Bateman, M.G., et al., Cardiac patient-specific three-dimensional models as surgical planning tools. Surgery, 2019.

5. Langridge, B., et al., Systematic Review of the Use of 3-Dimensional Printing in Surgical Teaching and Assessment. J Surg Educ, 2018. 75(1): p. 209-221.

6. Cacciamani, G.E., et al., Itimempact of Three-dimensional Printing in Urology: State of the Art and Future Perspectives. A Systematic Review by ESUT-YAUWP Group. Eur Urol, 2019.

7. Prasad, L.K. and H. Smyth, 3D Printing technologies for drug delivery: a review. Drug Dev Ind Pharm, 2016. 42(7): p. 1019-31.

8. Martelli, N., et al., Advantages and disadvantages of 3-dimensional printing in surgery: A systematic review. Surgery, 2016. 159(6): p. 1485-1500.

9. McCulloch, P., et al., No surgical innovation without evaluation: the IDEAL recommendations. Lancet, 2009. 374(9695): p. 1105-12.

10. Barkun, J.S., et al., Evaluation and stages of surgical innovations. Lancet, 2009. 374(9695): p. 1089-96.

11. Administration, T.G., Consultation: Proposed regulatory scheme for personalised medical devices, including 3D-printed devices, D.o. Health, Editor. 2019.

12. Jiang, M., et al., Three-dimensional printing in orthopaedic preoperative planning improves intraoperative metrics: a systematic review. ANZ J Surg, 2019. 
13. Diment, L.E., M.S. Thompson, and J.H.M. Bergmann, Clinical efficacy and effectiveness of 3D printing: a systematic review. BMJ Open, 2017. 7(12): p. e016891.

14. Tack, P., et al., 3D-printing techniques in a medical setting: a systematic literature review. Biomed Eng Online, 2016. 15(1): p. 115.

15. Witowski, J., et al., From ideas to long-term studies: 3D printing clinical trials review. Int J Comput Assist Radiol Surg, 2018. 13(9): p. 1473-1478.

16. Schuh, J.C.L. and K.A. Funk, Compilation of International Standards and Regulatory Guidance Documents for Evaluation of Biomaterials, Medical Devices, and 3-D Printed and Regenerative Medicine Products. Toxicol Pathol, 2019. 47(3): p. 344357.

17. Pradarelli, J.C., D.A. Campbell, Jr., and J.B. Dimick, Hospital credentialing and privileging of surgeons: a potential safety blind spot. JAMA, 2015. 313(13): p. 13134.

18. Pradarelli, J.C., J.P. Thornton, and J.B. Dimick, Who Is Responsible for the Safe Introduction of New Surgical Technology?: An Important Legal Precedent From the da Vinci Surgical System Trials. JAMA Surg, 2017. 152(8): p. 717-718.

19. Taylor vs Intuitive Surgical Inc., in Washington State Supreme Court 2017.

20. Pradarelli, J.C., J.M. Havens, and D.S. Smink, Facilitating the Safe Diffusion of Surgical Innovations. Ann Surg, 2019. 269(4): p. 610-611.

21. Stefanidis, D., et al., SAGES guidelines for the introduction of new technology and techniques. Surg Endosc, 2014. 28(8): p. 2257-71.

22. Neely, E.L., The Risks of Revolution: Ethical Dilemmas in 3D Printing from a US Perspective. Sci Eng Ethics, 2016. 22(5): p. 1285-1297. 


\section{TABLE}

Table $1 \quad$ Summary of key challenges, issues and related ethical concerns

\begin{tabular}{|c|c|c|c|}
\hline Trend & Issues & Ethical concerns & Pathways to solutions \\
\hline $\begin{array}{l}\text { Rapid adoption } \\
\text { and advances of } \\
\text { 3DP technologies }\end{array}$ & $\begin{array}{l}\text { - Use of new } \\
\text { technologies/procedures } \\
\text { prior to full evaluation } \\
\text { - } \text { Adoption can be influenced } \\
\text { by practical and market } \\
\text { considerations or by } \\
\text { conflicts of interest } \\
\text { - } \quad \text { Risks not fully understood }\end{array}$ & $\begin{array}{ll} & \text { Patient harms } \\
\text { - } & \text { Challenges to } \\
\text { (clinical) informed } \\
\text { consent } \\
\text { - } \\
\text { Distortion of } \\
\text { processes of fair/best } \\
\text { resource allocation }\end{array}$ & $\begin{array}{l}\text { Academic surgeons to } \\
\text { take a leadership role in } \\
\text { health advocacy and } \\
\text { engage actively with } \\
\text { stakeholders in } \\
\text { evaluation, ethical } \\
\text { transition and long-term } \\
\text { monitoring }\end{array}$ \\
\hline $\begin{array}{l}\text { Lack of } \\
\text { evidence-base }\end{array}$ & 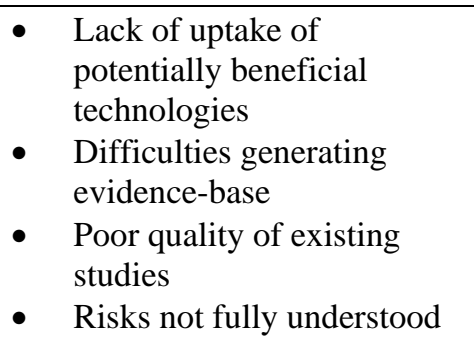 & $\begin{array}{l}\text { Patients receiving } \\
\text { suboptimal or no } \\
\text { treatments } \\
\text { Challenges to } \\
\text { (clinical) informed } \\
\text { consent }\end{array}$ & $\begin{array}{l}\text { Introduction of } \\
\text { prospective registries, } \\
\text { incentivising well- } \\
\text { conducted clinical trials } \\
\text { as well as regularly } \\
\text { updated meta-analyses } \\
\text { and systematic reviews }\end{array}$ \\
\hline Regulation & 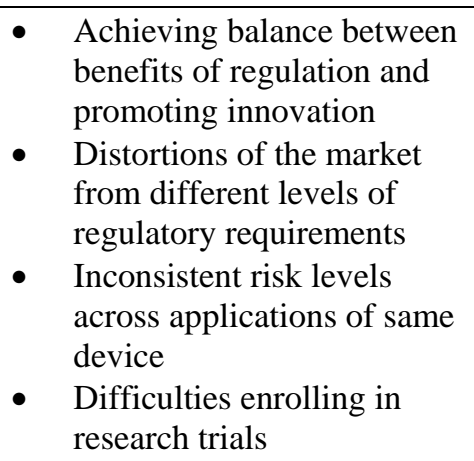 & $\begin{array}{l}\text { Patient harms from } \\
\text { under-regulation } \\
\text { versus } \\
\text { harms/opportunity } \\
\text { costs of too strict } \\
\text { regulation } \\
\text { - Impediment to } \\
\text { developing knowledge } \\
\text { to benefit patients }\end{array}$ & $\begin{array}{l}\text { Regulatory reform and } \\
\text { evaluation-based } \\
\text { implementation to allow } \\
\text { quicker adapting } \\
\text { regulatory schemes }\end{array}$ \\
\hline Implementation & $\begin{array}{ll}\text { - } & \text { Changing roles of surgeons } \\
\text { and hospitals } \\
\text { - } & \text { Responsibility for training } \\
\text { - } & \text { Changing integration of } \\
& \text { research and practice }\end{array}$ & $\begin{array}{l}\text { Ensuring safe and } \\
\text { effective } \\
\text { implementation of } \\
\text { new techs } \\
\text { - Conflict of interest if } \\
\text { training funded by } \\
\text { manufacturers }\end{array}$ & $\begin{array}{l}\text { Combined approach: } \\
\text { training with ongoing } \\
\text { proctoring, rigorous } \\
\text { hospital credentialing } \\
\text { processes, collaboration } \\
\text { with industry }\end{array}$ \\
\hline $\begin{array}{l}\text { IP and data } \\
\text { ownership }\end{array}$ & $\begin{array}{ll}\text { - } & \text { Potential for IP to stifle } \\
\text { - } & \text { Difnovation } \\
& \text { from 3DP } \\
\text { - } & \text { Surgeon as manufacturer } \\
\text { - } & \text { Possibility for unknowingly } \\
& \text { contravening IP }\end{array}$ & $\begin{array}{ll}\text { - } & \text { Privacy of individual } \\
\text { patient data } \\
\text { - } & \text { Protection of IP of } \\
\text { individual innovators } \\
\text { - } & \text { Protection of role of } \\
\text { IP systems in } \\
\text { supporting innovation } \\
\text { - } \\
\text { Potential harms } \\
\text { related to data } \\
\text { ownership procedures }\end{array}$ & $\begin{array}{l}\text { Data privacy } \\
\text { laws/regulation }\end{array}$ \\
\hline
\end{tabular}




\section{University Library}

\section{- M M I N E R VA \\ A gateway to Melbourne's research publications}

Minerva Access is the Institutional Repository of The University of Melbourne

Author/s:

Kemp, S;Coles-Black, J;Walker, MJ;Wallace, G;Chuen, J;Mukherjee, P

Title:

Ethical and regulatory considerations for surgeons as consumers and creators of threedimensional printed medical devices

Date:

2020-07-01

Citation:

Kemp, S., Coles-Black, J., Walker, M. J., Wallace, G., Chuen, J. \& Mukherjee, P. (2020). Ethical and regulatory considerations for surgeons as consumers and creators of three-dimensional printed medical devices. ANZ JOURNAL OF SURGERY, 90 (7-8), pp.1477-1481. https://doi.org/10.1111/ans.15871.

Persistent Link:

http://hdl.handle.net/11343/275566 